\title{
The Effect of Witnessing Parental Violence on Perpetration of Violence in the Military in South Korea
}

\author{
A focus on the mediating effect of tolerance of violence on perpetration of violence
}

[ Yujin Lee \& Jae Yop Kim]

This study examines the causal relationship between witnessing parental violence and perpetration of violence in the military, and also examines the mediating effect of tolerance of violence between soldiers. A total of 1,000 military personnel (Army, Navy, and Air Force) in South Korea completed questionnaires related to witnessing violence between parents, perpetration of violence in the military, and tolerance of violence. Data were analyzed using SPSS 21.0 for descriptive statistics, frequency, t-test, and Poisson regression, and the results are as follows. First, approximately $26.2 \%$ of participants responded to having witnessed parental violence. Second, the effect of witnessing parental violence on perpetration of violence was statistically significant, and third, the mediating effect of tolerance of violence on perpetration of violence in the military was verified. Based on the results of this study, we discuss practical and policy-based interventions for witnessing parental violence and perpetration of violence in the military.

Keywords-military social work, enlisted soldiers, witnessing parental violence, tolerance of violence, perpetration of violence in the military

Yujin Lee

line 1 Yonsei University

line 2: South Korea

Jae Yop Kim

line 1 Yonsei University

line 2: South Korea 